\title{
A Comparative Study of Non-Volatile Compounds Present in 3R4F Cigarettes and iQOS Heatsticks Utilizing GC-MS
}

\author{
Miguel Peñin Ibañez, Daniel Martin, Alicia González Gonzálvez, Helmut H. Telle, \\ Ángel González Ureña* \\ Departamento de Química Física Aplicada, Facultad de Ciencias, Universidad Autónoma de Madrid, Madrid, Spain \\ Email: *angel.gonzalezu@uam.es
}

How to cite this paper: Ibañez, M.P., Martin, D., Gonzálvez, A.G., Telle, H.H. and Ureña, Á.G. (2019) A Comparative Study of Non-Volatile Compounds Present in 3R4F Cigarettes and iQOS Heatsticks Utilizing GC-MS. American Journal of Analytical Chemistry, 10, 76-85.

https://doi.org/10.4236/ajac.2019.103007

Received: January 25, 2019

Accepted: March 5, 2019

Published: March 8, 2019

Copyright $\odot 2019$ by author(s) and Scientific Research Publishing Inc. This work is licensed under the Creative Commons Attribution International License (CC BY 4.0).

http://creativecommons.org/licenses/by/4.0/

\begin{abstract}
It is now widely suggested that people who are dependent on nicotine should switch from ordinary tobacco smoking to alternative products, which at least reduce the overall harm from smoking. A number of alternatives are now popular, including electronic cigarettes and heatsticks. In this work comparative analysis of the smoke/aerosol emission from 3R4F standard cigarettes and iQOS heatsticks was undertaken. For this, gas chromatography-mass spectrometry (GC-MS) analysis was applied, to measure the non-volatile compounds of smoke/aerosol emission from individual samples, with the specific aim to determine their content of nicotine and selected other main components. All measurement data were collected under the Health Canada Intense (HCI) puffing regime. The most relevant findings of the present investigation can be summarized as follows. First, the number of measured aerosol components in the iQOS samples, with respect to those of 3R4F samples, was significantly lower (notably 37 versus 12 components). Second, the analysis of the iQOS and 3R4F GC-MS chromatographic fingerprints indicated a non-nicotine global component reduction (number and areas excluding nicotine) of larger than $80 \%$ for the iQOS samples in comparison to $3 \mathrm{R} 4 \mathrm{~F}$ samples. Third, the nicotine content of the iQOS aerosol was less than half that contained in the $3 \mathrm{R} 4 \mathrm{~F}$ smoke. The results from the present investigation indicate that-except for nicotine-smokers are exposed to a largely reduced number and amount of non-volatile, non-nicotine components in the iQOS heatstick aerosol, in comparison to those in the $3 \mathrm{R} 4 \mathrm{~F}$ cigarette smoke.
\end{abstract}

\section{Keywords}

Cigarette, Heatstick, Chromatographic Analysis, Nicotine, Tobacco Harm Reduction (THR) 


\section{Introduction}

In 2007, the Royal College of Physicians RCP published a report, Harm reduction in nicotine addiction [1], dedicated to harm-reduction strategies to tobacco dependence. In this report, it was argued that "as most of the harm caused by smoking arises not from nicotine but from other components of tobacco smoke, the health and life expectancy of today's smokers could be radically improved by encouraging as many as possible to switch to a smoke-free source of nicotine" [2]. This proposal initiates the so-called principle of Tobacco Harm Reduction (THR) [3] [4] [5] [6], which nowadays constitutes an active health strategy to lower the individual's and society's health risk from using tobacco products (see for example [6]).

Two of the most relevant alternatives to tobacco products, i.e. conventional combustion cigarettes, are: 1) the electronic nicotine delivery systems (ENDS), also called e-cigarettes-see e.g. [7] [8] for a general discussion of ENDS; [9] [10] for comparative studies of the effect of ENDS on active and passive smokers; or [11] [12] for general literature reviews; and 2) tobacco heated systems (THS), also addressed as heat-not-burn tobacco products (HNB) - see e.g. [13] [14] for a general discussion of THS2.2 devices; [15] [16] for studies comparing the emission from THSs with that of ordinary cigarettes; or [17] [18] for modelling of aerosol formation in THSs and their analysis. Note that one of the THSs is commercially known as iQOS, which is the THS used in the present investigation.

While in ENDS an aerosol is produced; when a nicotine solution (usually in propylene glycol, glycol and water) is vaporized, in THS tobacco is heated, but not burnt. In both systems, the operating temperatures are of the order $300^{\circ} \mathrm{C}$ $350^{\circ} \mathrm{C}$, i.e. substantially lower than those encountered for ordinary cigarettes (in the range $650^{\circ} \mathrm{C}-900^{\circ} \mathrm{C}$ ). Therefore, the combustion process that generates the smoke with many toxic compounds is avoided. For example, Schaller et al. [13] [14] compared the chemical composition of THS aerosols with that of smoke from reference $3 \mathrm{R} 4 \mathrm{~F}$ cigarettes, finding an average reduction by over $90 \%$ in Harmful and Potentially Harmful Constituents (HPHCs).

Numerous independent studies have been carried out, focusing by and large on the comparison between the emission of a range of compounds from iQOS, e-cigarettes and conventional (combustion) cigarettes. These include studies aiming at the analysis of the general chemical composition of the emitted smoke/aerosol [19] [20] [21]; the analysis for specific chemical compounds, such as e.g. nicotine or toxic compounds [22] [23] [24]; assessing medical impact issues related to using any of the smoking products [25] [26] [27]; and highlighting the advantages of iQOS with respect to conventional smoking, but also pointing out potential caveats [28] [29] [30] [31]. Overall, the majority of studies support the tobacco harm reduction (THR) in the uptake of "smoke" from heated or electronic cigarettes when compared to traditional tobacco smoke.

The main objectives of the present study were: 1) to measure the chroma- 
tographic fingerprints originating from the 3R4F cigarette and the HEETS heatstick (hereafter denoted as iQOS), allowing for a direct comparison between the main components of their smoke/aerosol; and 2) to determine the nicotine content of the 3R4F smoke and the iQOS aerosol, respectively. Note that, here we report only on the non-volatile compounds present in both types of cigarettes; a forthcoming study will focus on volatile compounds present in the same type of cigarettes.

\section{Materials and Methods}

The 3R4F and iQOS samples used in this study were provided by Philip Morris. All chemicals-nicotine standards, methanol, water, etc.-were purchased from Sigma-Aldrich.

In Figure 1 the experimental setup employed for the smoke and aerosol collection is illustrated. The basic "smoking machine" follows the well-established methodology based on liquid traps (see for example [6]) and consists of 1) one or two liquid traps, depending on the experimental conditions; 2) a programmable flowmeter; and 3) a vacuum system. In a typical run, the flowmeter setting was adjusted to the desired flow rate, with the vacuum pump on, using a conventional cigarette. Subsequently, for the puffing regime appropriate values were set and measurement runs were initiated, each time using a new volume of liquid in the trap and a new cigarette sample, either the 3R4F or the heatstick.

All measurements taken during the present investigation were implemented under the Health Canada Intense ( $\mathrm{HCl})$ puffing regime [32], i.e. the puff time and volume were $2 \mathrm{~s}$ and $55 \mathrm{~mL}$, respectively, with a time interval of $30 \mathrm{~s}$ between successive puffs. Although the solvent and volume employed in the liquid traps obviously depend on the analyte to be determined, for the nicotine quantification and GC-MS measurements (see further below) a total volume of $100 \mathrm{~mL}$ of methanol in only one trap proved to be enough to produce accurate, quantitative results. This trapping protocol was selected after several trial-and-error determinations to ensure that the use of one trap and $100 \mathrm{~mL}$ volume guaranteed the total collection of the nicotine present in the aerosol; notably, the use of a larger volume in the same, or additional trap(s), hardly changed the total nicotine collection.

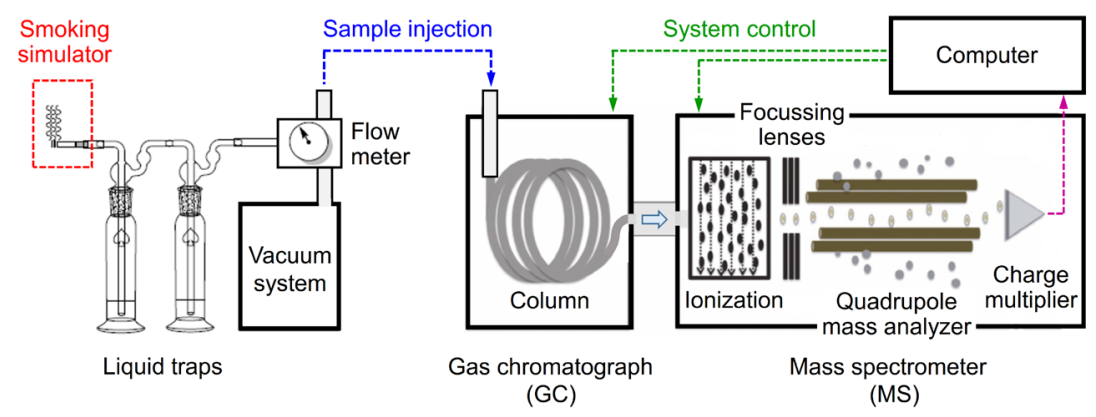

Figure 1. Experimental setup of the smoking simulator, with sample preparation (left) and the GC-MS analytical method (right). For details see text. 
GC/MS analysis of the samples was performed using a GC-MS Bruker 436GC and an EVOQGC detector. The GC separation was carried out using a Factor IV $(30 \mathrm{~m} \times 0.25 \mathrm{~mm} \times 0.1 \mu \mathrm{m})$ column with the GC oven temperature programmed from $40^{\circ} \mathrm{C}(2 \mathrm{~min})$ to $140^{\circ} \mathrm{C}$ at $10^{\circ} \mathrm{C} \cdot \mathrm{min}^{-1}$, and then to $250^{\circ} \mathrm{C}$ at $20^{\circ} \mathrm{C} \cdot \mathrm{min}^{-1}$ with a final isothermal hold at $250^{\circ} \mathrm{C}$ for $1 \mathrm{~min}$. The sample was injected in a split-less mode at an injector temperature of $280^{\circ} \mathrm{C}$ and scanned from 40 to 350 amu using electron impact (EI) mode. The He-flux was $1 \mathrm{~mL} \cdot \mathrm{min}^{-1}$ and the injection volume $1 \mu \mathrm{L}$.

It should be noted that the use of other trapping elements like, for example, solid filters to collect volatile compounds [23] was not considered because in the present investigation we wished to focus on the presence of non-volatile compounds. It should be pointed out that methanol may also trap some volatile compounds. However, under the experimental conditions of the present investigation, their chromatogram peaks will overlap with that of the methanol solvent. The study and comparison of volatile compounds will be the subject of a forthcoming paper.

\section{Results and Discussion}

\subsection{GC-MS Analysis of the 3R4F and iQOS Samples}

In this section chromatograms for both $3 \mathrm{R} 4 \mathrm{~F}$ and iQOS are presented. The data correspond to smoke or aerosol collection from three samples for each the iQOS and 3R4F specimen, averaged over ten repeat measurements.

Figure 2 shows a comparison between the two chromatograms in which an offset of 0.2 has been introduced for clarity. Before a detailed description of the results it is worth noting that cigarette smoke is a complex mixture, which contains more than 6000 chemicals [33]; consequently, no single method could

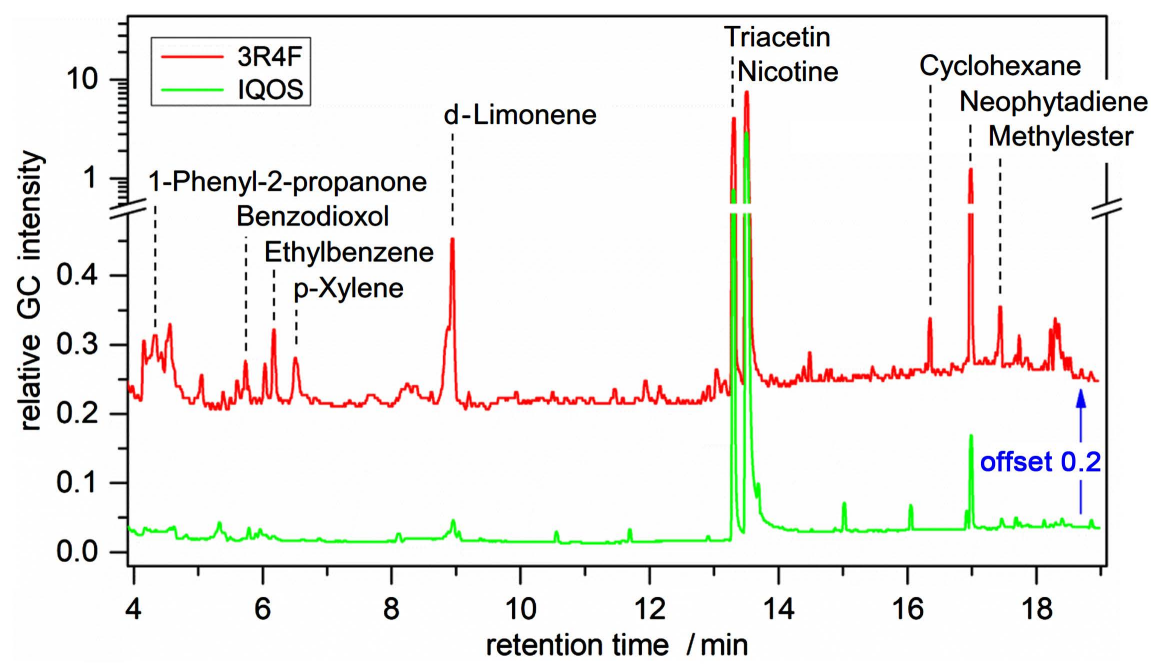

Figure 2. Comparison between the 3R4F and iQOS chromatograms, measured by GC-MS for the retention time interval 4 - 19 minutes. Peaks for selected compounds are annotated; note the significant reduction or absence of many peaks in the iQOS sample. For details see text. 
possibly trap all chemicals and, therefore, the results presented in Figure 2 include only part of the overall chemical composition of 3R4F cigarette smoke and iQOS heatstick aerosol.

The annotated peaks correspond to stable species whose identification was carried out by comparing the measured mass spectrum for every GC component at a given retention time-denoted as target spectrum-with those available from the NIST library incorporated in the GC-MS software. Typically, the software selects as best candidate the one whose library fragmentation pattern shows the highest degree of similarity with that of measured one.

A closer inspection of the peak intensity distribution reveals two significant differences between the two chromatograms.

First, many peaks in the iQOS spectrum are absent, in comparison to that of 3R4F. While for the reference $3 \mathrm{R} 4 \mathrm{~F}$ cigarette one counts as many as 37 , in the iQOS sample this number reduces to no more than 12 (above the noise level of these measurements).

Second, a significant reduction in amplitude is observed for most peaks still present-as for example those of nicotine, d-limonene (shown to have very low toxicity in humans), or tetracin (normally not deemed to be toxic), to cite the most dominant in the GC spectrum.

Third, many peaks present in the 3R4F sample-like 1-Phenyl-2-propanone, also known as phenylacetone, and benzodioxol (both classified as toxic on inhalation); ethylbenzene (thought to be carcinogenic); p-xylene (potentially causing lung damage); or some cyclohexane derivatives (thought to be of low toxicity)-are absent (or present below the noise limit) in the IOQS aerosol.

\subsection{Sample Assessment Based on Peak-Area Distribution}

The reduction of the number of components in the iQOS aerosol compared to those of the 3R4F smoke can also be seen in a more pictorial manner by inspecting the histogram plots in which the peak-area distributions of said components are shown as a function of the retention time for both samples (see Figure 3).

An overall reduction of both the number and concentration of compounds was observed. In a semi-quantitative manner, the total reduction fraction (TRF) was estimated to be

$$
\mathrm{TRF}=\left(8.62 \times 10^{9}\right) /\left(2.69 \times 10^{10}\right) \approx 0.32
$$

The numerical values inside the parenthesis correspond to the sum of the areas of the complete series of peaks obtained in the GC-MS chromatograms. Interestingly, the non-nicotine total reduction fraction (NNTRF) is given by

$$
\mathrm{NNTRF}=\left[\left(8.62 \times 10^{9}-6.55 \times 10^{9}\right) /\left(2.69 \times 10^{10}-1.29 \times 10^{10}\right)\right]=0.148 \approx 0.15
$$

In other words, one obtains an overall reduction in non-nicotine compounds of $85 \%$. However, one should point out that this is only a semi-quantitative indicator since only by a full measurement of the concentration for all components 


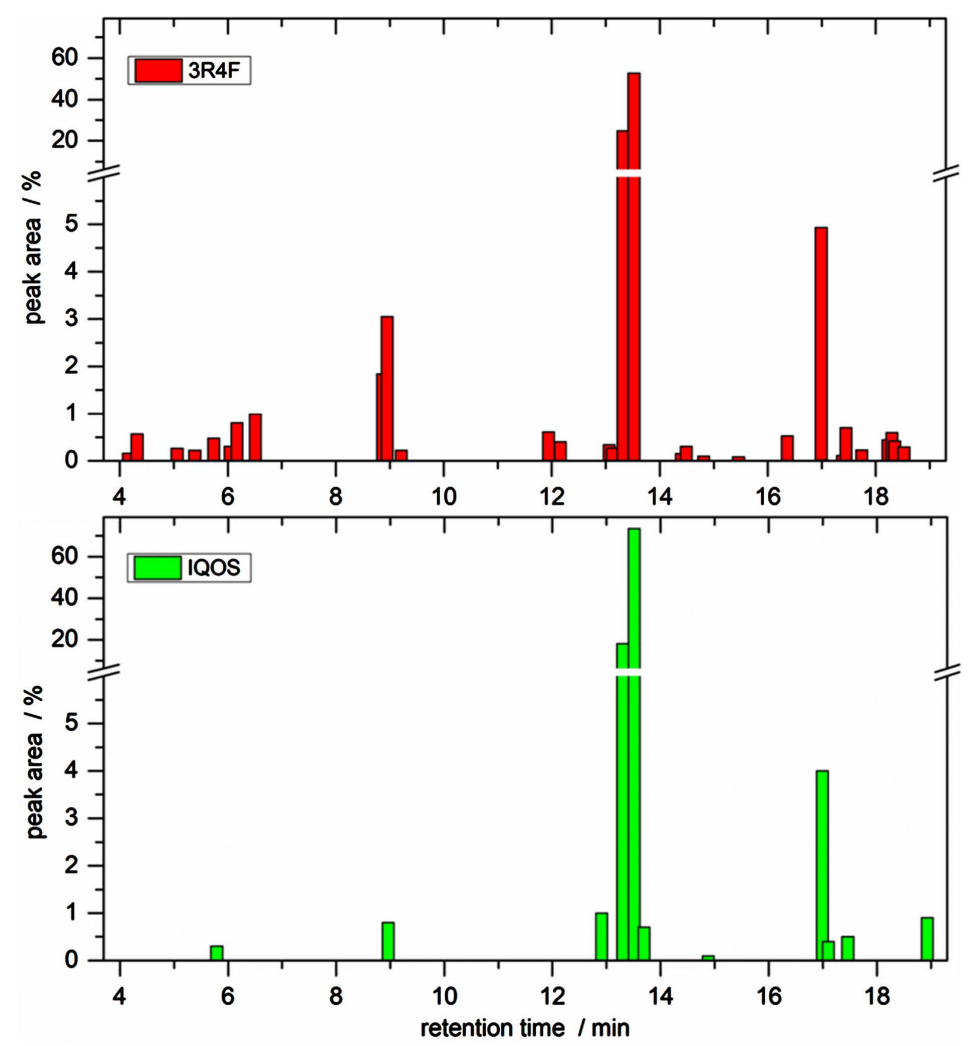

Figure 3. Peak-area distribution versus retention time for the 3R4F cigarette (top) and for the iQOS heatstick (bottom).

(also including volatile compounds) one could obtain a fully quantitative meaning for such indicator.

The low value of NNTRF, i.e. the strong reduction of non-nicotine compounds observed in the iQOS aerosol compared with that of 3R4F smoke can be explained by the distinct reaction mechanisms responsible for their production in both systems. In fact, in the $3 \mathrm{R} 4 \mathrm{~F}$ cigarette the smoke is produced by the tobacco combustion at about $850^{\circ} \mathrm{C}-900^{\circ} \mathrm{C}$, a "chemical scenario" in which not only many radical reactions are present but, in addition, their reaction rates are thermally activated due to the high temperature. In contrast, the iQOS aerosol produced by the tobacco heating to only about $350^{\circ} \mathrm{C}$, without combustion, is characterised by the absence of many radical reactions and by lower reaction rates of the reactive species still present, associated with the much lower temperature of the (gaseous) aerosol mixture.

\subsection{Nicotine Content in the Smoke/Aerosol Samples}

A nicotine calibration curve was obtained by measuring the peak area from twelve standard nicotine solutions ranging from $40 \mathrm{mg} / \mathrm{L}$ up to $200 \mathrm{mg} / \mathrm{L}$. A good linear correlation was found with a $\mathrm{R}^{2}=0.998$.

Using this calibration, Table 1 lists the nicotine content of the $3 \mathrm{R} 4 \mathrm{~F}$ cigarette and iQOS heatstick samples, respectively. The data are expressed as the mean value of three measurements for each sample at $95 \%$ confidence level. 
Table 1. Nicotine content in individual 3R4F cigarette and iQOS heatstick samples.

\begin{tabular}{cccc}
\hline Specimen & Nicotine $(\mathrm{mg} /$ sample $)$ & Mean $\pm \mathrm{CI}_{95 \%}(\mathrm{mg} /$ sample $)$ & Reference \\
\hline 3R4F & - & $2.09 \pm 0.14$ & {$[14]$} \\
$3 \mathrm{R} 4 \mathrm{~F}$ & 2.19 & & \\
& 2.30 & $2.26 \pm 0.06$ & This work \\
& 2.28 & & \\
& 1.14 & & This work \\
iQOS & 1.14 & $1.15 \pm 0.02$ & \\
\hline
\end{tabular}

Our result for the $3 \mathrm{R} 4 \mathrm{~F}$ specimen is compared to the value reported by Schaller et al. [14]; the two values are in satisfactory agreement with each other. The result for the iQOS specimen suggests a reduction of $\sim 51 \%$ in the nicotine content in comparison to that of $3 \mathrm{R} 4 \mathrm{~F}$.

\section{Conclusions}

The most relevant conclusions that can be drawn from the present study are as following. First, the experimental conditions under which the present investigations were carried out, coupled with the part-per-billion (ppb) sensitivity of the GC-MS equipment used here, allow one to identify many (non-volatile) compounds, many of which are present at only ultra-low concentrations in the cigarette smoke/aerosol. Second, the non-nicotine composition-profile of the iQOS aerosol appears to be significantly simpler than that of 3R4F smoke-a total of 37 compounds are seen for the 3R4F specimen, a number of which reduces to 12 for the iQOS aerosol. Third, the comparison between the iQOS and 3R4F GC-MS chromatographic fingerprints indicates that the global component reduction (number and areas excluding nicotine) is $85 \%$; i.e. the non-nicotine iQOS global content is only $15 \%$ of that of $3 \mathrm{R} 4 \mathrm{~F}$.

Hence, except for nicotine, one may conclude that potentially the smoke from the $3 \mathrm{R} 4 \mathrm{~F}$ cigarette and the aerosol from iQOS might affect smokers-as well as passive smokers-differently, in terms of exposure to non-nicotine components. Of course, the effects of volatile compounds, not covered in this study, need yet to be considered.

As a final point it is noteworthy that the nicotine content of the iQOS aerosol is just half that of the nicotine contained in the $3 \mathrm{R} 4 \mathrm{~F}$ smoke. Work is now in progress in our laboratory to extend this type of investigation not only to the analysis of volatile compounds but also to a wider range of new tobacco products presently available on the market.

\section{Acknowledgements}

This work received financial support from Philip Morris Spain; the authors gratefully acknowledge the provision of heatstick devices and 3R4F cigarettes. 


\section{Conflicts of Interest}

The authors declare no conflicts of interest with respect to the research, authorship, and publication of this article.

\section{References}

[1] Tobacco Advisory Group of the Royal College of Physicians (2007) Harm Reduction in Nicotine Addiction. Royal College of Physicians, London. http://hams.cc/tobaccol/tobacco.pdf

[2] Royal College of Physicians (2016) Nicotine without Smoke: Tobacco Harm Reduction. London.

[3] Rodu, B. and Godshall, W.T. (2006) Tobacco Harm Reduction: An Alternative Cessation Strategy for Inveterate Smokers. Harm Reduction Journal, 3, 37. https://doi.org/10.1186/1477-7517-3-37

[4] Bates, C., Fagerstrom, K., Jarvis, M.J., Kunze, M., McNeill, A. and Ramstrom, L. (2003) European Union Policy on Smokeless Tobacco: A Statement in Favour of Evidence-Based Regulation for Public Health. Tobacco Control, 12, 360-367. https://doi.org/10.1136/tc.12.4.360

[5] Rodu, B. and Nitzkin, J.L. (2010) Update on the Scientific Status of Tobacco Harm Reduction 2008-2010. American Association of Public Health Physicians. https://www.aaphp.org/special/joelstobac/2010/harmredcnupdatejuly2010.html/

[6] Tobacco Harm Reduction (THR) Summit Spain. Barcelona. http://thrsummitspain.org/index.php/resources/

[7] Breland, A., Soule, E., Lopez, A., Ramoa, C., El-Hellani, A. and Eissenberg, T. (2017) Electronic Cigarettes: What Are They and What Do They Do? Annals of the New York Academy of Sciences, 1394, 5-30. https://doi.org/10.1111/nyas.12977

[8] Lopez, A.A. and Eissenberg, T. (2015) Science and the Evolving Electronic Cigarette. Preventive Medicine, 80, 101-106. https://doi.org/10.1016/j.ypmed.2015.07.006

[9] Logue, J.M., Sleiman, M., Montesinos, V.N., Russell, M.L., Litter, M.I., Benowitz, N.L., Gundel, L.A. and Destaillats, H. (2017) Emissions from Electronic Cigarettes: Assessing Vapers' Intake of Toxic Compounds, Second-Hand Exposures, and the Associated Health Impacts. Environmental Science \& Technology, 51, 9271-9279. https://doi.org/10.1021/acs.est.7b00710

[10] Gallart-Mateu, D., Elbal, L., Armenta, S. and de la Guardia, M. (2016) Passive Exposure to Nicotine from E-Cigarettes. Talanta, 152, 329-334. https://doi.org/10.1016/j.talanta.2016.02.014

[11] Glasser, A.M., Collins, L. and Pearson, J.L. (2017) Overview of Electronic Nicotine Delivery Systems: A Systematic Review. American Journal of Preventive Medicine, 52, e33-e66. https://doi.org/10.1016/j.amepre.2016.10.036

[12] Zulkifli, A., Abidin, E.Z., Abidin, N.Z., Amer Nordin, A.S., Praveena, S.M., Syed Ismail, S.N., Rasdi, I., Karuppiah, K. and Rahman, A.A. (2018) Electronic Cigarettes: A Systematic Review of Available Studies on Health Risk Assessment. Reviews on Environmental Health, 33, 43-52. https://doi.org/10.1515/reveh-2015-0075

[13] Schaller, J.P., Keller, D., Poget, L., Pratte, P., Kaelin, E., McHugh, D., Cudazzo, G., Smart, D., Tricker, A.R., Gautier, L., Yerly, M., Pires, R.R., Le Bouhellec, S., Ghosh, D., Hofer, I., Garcia, E., Vanscheeuwijck, P. and Maeder, S. (2016) Evaluation of the Tobacco Heating System 2.2. Part 2: Chemical Composition, Genotoxicity, Cyto- 
toxicity, and Physical Properties of the Aerosol. Regulatory Toxicology and Pharmacology, 81, S27-S47. https://doi.org/10.1016/j.yrtph.2016.10.001

[14] Schaller, J.P., Pijnenburg, J.P., Ajithkumar, A. and Tricker, .AR. (2016) Evaluation of the Tobacco Heating System 2.2. Part 3: Influence of the Tobacco Blend on the Formation of Harmful and Potentially Harmful Constituents of the Tobacco Heating System 2.2 Aerosol. Regulatory Toxicology and Pharmacology, 81, S48-S58. https://doi.org/10.1016/j.yrtph.2016.10.016

[15] Jaccard, G., Tafin Djoko, D., Moennikes, O., Jeannet, C., Kondylis, A. and Belushkin, M. (2017) Comparative Assessment of HPHC Yields in the Tobacco Heating System THS 2.2 and Commercial Cigarettes. Regulatory Toxicology and Pharmacology, 90, 1-8. https://doi.org/10.1016/j.yrtph.2017.08.006

[16] Pratte, P., Cosandey, S. and Goujon Ginglinger, C. (2017) Investigation of Solid Particles in the Mainstream Aerosol of the Tobacco Heating System THS 2.2 and Mainstream Smoke of a 3R4F Reference Cigarette. Human \& Experimental Toxicology, 36, 1115-1120. https://doi.org/10.1177/0960327116681653

[17] Nordlund, M. and Kuczaj, A.K. (2016) Modeling Aerosol Formation in an Electrically Heated Tobacco Product. International Journal of Chemical, Molecular, Nuclear, Materials and Metallurgical Engineering, 10, 326-338.

[18] Poget, L., Campelos, P., Jeannet, C. and Maeder, S. (2017) Development of Models for the Estimation of Mouth Level Exposure to Aerosol Constituents from a Heat-Not-Burn Tobacco Product Using Mouthpiece Analysis. Beiträge zur Tabakforschung International, 27, 42-64. https://doi.org/10.1515/cttr-2017-0005

[19] Bekki, K., Inaba, Y., Uchiyama, S. and Kunugita, N. (2017) Comparison of Chemicals in Mainstream Smoke in Heat-Not-Burn Tobacco and Combustion Cigarettes. Journal of UOEH, 39, 201-207. https://doi.org/10.7888/juoeh.39.201

[20] Forster, M., Fiebelkorn, S., Yurteri, C., Mariner, D., Liu, C., Wright, C., McAdam, K., Murphy, J. and Proctor, C. (2018) Assessment of Novel Tobacco Heating Product THP1.0. Part 3: Comprehensive Chemical Characterisation of Harmful and Potentially Harmful Aerosol Emissions. Regulatory Toxicology and Pharmacology, 93, 14-33. https://doi.org/10.1016/j.yrtph.2017.10.006

[21] Li, X., Luo, Y., Jiang, X., Zhang, H., Zhu, F., Hu, S., Hou, H., Hu, Q. and Pang, Y. (2019) Chemical Analysis and Simulated Pyrolysis of Tobacco Heating System 2.2 Compared to Conventional Cigarettes. Nicotine \& Tobacco Research, 21, 111-118. https://doi.org/10.1093/ntr/nty005

[22] Veronese, C., Ruprecht, A.A., de Marco, C., Ogliari, A.C., Allegri, F., Munarini, E., Angellotti, G., Mazza, R. and Boffi, R. (2017) Fumo di sigaretta, vapore di e-cig e "fumo freddo": Un confronto tra le emissioni di sostanze nocive [Cigarette Smoke, E-Cig Vapor and "Heat-Not-Burn": A Comparison between the Emissions of Toxic Compounds]. Tabaccologia, 1, 17-23.

http://www.tabaccologia.it/filedirectory/PDF/1_2017/06-tabaccologia1_2017.pdf

[23] Ruprecht, A.A., De Marco, C., Saffari, A., Pozzi, P., Mazza, R., Veronese, C., Angellotti, G., Munarini, E., Ogliari, A.C., Westerdahl, D., Hasheminassab, S., Shafer, M.M., Schauer, J.J., Repace, J., Sioutas, C. and Boffi, R. (2017) Environmental Pollution and Emission Factors of Electronic Cigarettes, Heat-Not-Burn Tobacco Products and Conventional Cigarettes. Aerosol Science and Technology, 51, 674-684. https://doi.org/10.1080/02786826.2017.1300231

[24] Farsalinos, K.E., Yannovits, N., Sarri, T., Voudris, V. and Poulas, K. (2018) Nicotine Delivery to the Aerosol of a Heat-Not-Burn Tobacco Product: Comparison with a Tobacco Cigarette and E-Cigarettes. Nicotine \& Tobacco Research, 18, 1004-1009. 
https://doi.org/10.1093/ntr/ntx138

[25] Protano, C., Manigrasso, M., Avino, P., Sernia, S. and Vitali, M. (2016) Second-Hand Smoke Exposure Generated by New Electronic Devices (iQOS ${ }^{\circledR}$ and E-Cigs) and Traditional Cigarettes: Submicron Particle Behaviour in Human Respiratory System. Ann Ig, 28, 109-112.

[26] Protano, C., Manigrasso, M., Avino, P. and Vitali, M. (2017) Second-Hand Smoke Generated by Combustion and Electronic Smoking Devices Used in Real Scenarios: Ultrafine Particle Pollution and Age-Related Dose Assessment. Environment International, 107, 190-195. https://doi.org/10.1016/j.envint.2017.07.014

[27] Miyashita, L. and Grigg, J. (2018) Effect of the iQOS Electronic Cigarette Device on Susceptibility to $S$. pneumoniae Infection. Journal of Allergy and Clinical Immunology, 141, AB28. https://doi.org/10.1016/j.jaci.2017.12.090

[28] Caputi, T.L., Leas, E., Dredze, M., Cohen, J.E. and Ayers, J.W. (2017) They're Heating Up: Internet Search Query Trends Reveal Significant Public Interest in Heat-Not-Burn Tobacco Products. PLoS ONE, 12, e0185735. https://doi.org/10.1371/journal.pone.0185735

[29] Kim, M. (2018) Philip Morris International Introduces New Heat-Not-Burn Product, iQOS, in South Korea. Tobacco Control, 27, e76-e78. https://doi.org/10.1136/tobaccocontrol-2017-053965

[30] Caruso, M. and Polosa, R. (2017) Perplexing Conclusions Concerning Heat-Not-Burn Tobacco Cigarettes. JAMA Internal Medicine, 177, 1699. https://doi.org/10.1001/jamainternmed.2017.5843

[31] Davis, B., Williams, M. and Talbot, P. (2019) iQOS: Evidence of Pyrolysis and Release of a Toxicant from Plastic. Tobacco Control, 28, 34-41.

[32] ISO/TR 19478-2:2015(en). ISO and Health Canada Intense Smoking Parameters Part 2: Examination of Factors Contributing to Variability in the Routine Measurement of TPM, Water and NFDPM Smoke Yields of Cigarettes. https://www.iso.org/obp/ui/\#iso:std:iso:tr:19478:-2:ed-1:v1:en

[33] Rodgman, A. and Perfetti, T.A. (2009) The Chemical Components of Tobacco and Tobacco Smoke. CRC Press, Boca Raton. 